American Journal of Pharmacology and Toxicology 2 (2): 60-64, 2007

ISSN 1557-4962

(C) 2007 Science Publications

\title{
Zonisamide: The Arizona Experience
}

\author{
${ }^{1}$ K.J. Oommen and ${ }^{2}$ Enriqe Labadie \\ ${ }^{1}$ Department of Neurology, Comprehensive Oklahoma Program for Epilepsy, Oklahoma City, Oklahoma \\ ${ }^{2}$ Department of Neurology, University of Arizona Health Sciences Center, Tucson Arizona
}

\begin{abstract}
Zonisamide (ZNS) is a new antiepileptic drug initially introduced in Europe, Japan and the United States (US) in the late 1980's and was the first such drug to be clinically tested in the US, since the marketing of valproic acid in 1978. Reports of nephrolithiasis by European and US investigators resulted in the trials being terminated in the US during the open label phase. The present report is the result of a non-blind, historical controlled study of the safety and efficacy of zonisamide conducted at the University of Arizona as part of a nine-center US trial. Twenty patients, ten male and ten female, aged 18-54 were enrolled. Nineteen patients received zonisamide code named CI-912 at a dosage of $6.2-14 \mathrm{mg} \mathrm{kg}^{-1}$. Sixteen patients completed the study. Efficacy was defined as $>50 \%$ reduction in seizures. Zonisamide was effective in reducing partial seizures with or without secondary generalization in $56.3 \%$ of patients who completed the study. No patient had significant alteration in $\mathrm{CBC}$ and SMA 16 requiring adjustment of dosage. The average plasma levels ranged from 10 to $31 \mathrm{ug}$ $\mathrm{mL}^{-1}$ during treatment. The only major side effect that required discontinuation of treatment was the development of a skin rash in one patient. Two others discontinued the study due to personal reasons.
\end{abstract}

Key words: Zonisamide, seizures, epilepsy, antiepileptic, sulfonamide

\section{INTRODUCTION}

Epilepsy has an age adjusted prevalence of 0.625 per $1000^{[1]}$. Estimates of people with the condition in the US range from 1.5 to 3 million $^{[2]}$. Clinicians treating patients with epilepsy were acutely aware of the fact that the traditional antiepileptic drugs (AEDs) did not provide complete seizure control for all and that treatment may result in serious side effects in some. The first major attempt at comparing the efficacy of these drugs was the VA co-operative study ${ }^{[3]}$. It showed that the majority of patients with seizures may be treated successfully by a single anti-epileptic drug, but that $32 \%$ of the patients enrolled in the study dropped out because of side effects of the drug or due to lack of seizure control. Thus the study demonstrated the need for more effective and less toxic anti-epileptic drugs. The search was on and zonisamide became the, first AED to be clinically tried in this country, 15 years after the marketing of valproic acid. However, with the report of renal stones, marketing attempts were abandoned in USA and Europe. However, the Japanese experience where it was in use since 1989 , caused a renewed interest in bringing the drug to the USA. The newly completed studies in the USA resulted in the FDA granting an approvable status to the drug in March
1998. It is available for general prescription use, as addon therapy for partial seizures in this country, since April 2000.

The objectives of the study were to (a) determine the efficacy of zonisamide (CI-912) as an antiepileptic drug, (b) determine the plasma levels of zonisamide at therapeutic doses and (c) obtain information on the safety of the drug as measured by the frequency and severity of side effects.

\section{MATERIALS AND METHODS}

The Arizona experience was derived from patients who received the drug through the out patient clinics of the Department of Neurology, of the Arizona Health Sciences Center (AHSC) as part of the first multicenter trial of the drug in the USA. Subjects were enrolled after signing informed consent approved by the Human Subjects Committee of the AHSC. The protocol allowed the inclusion of male and female patients, 18-65 years of age with at least four simple or complex partial seizures alone or with secondary generalization per month, on the average, in the four months prior to entry, on at least one and not more than three antiepileptic medications, with therapeutic levels. The study period consisted of a twelve-

Corresponding Author: $\quad$ K.J. Oommen, M.D., Department of Neurology, 711 Stanton Young Blvd., Suite 215, Oklahoma City, OK 73072, Tel: 405-271-4113 
week control, four-week titration of zonisamide (CI-912) and a final twelve weeks of continued treatment. The seizure types and frequency, physical and neurological status, hematologic and chemical profiles, antiepileptic drug levels and side effects were monitored throughout this period. Effectiveness was defined as a $50 \%$ or greater reduction in seizure frequency during the treatment period compared to the baseline. Side-effects were recorded as reported by the patient during follow-up visits while the patients were receiving the medication.

\section{RESULTS}

Twenty patients were enrolled in the study. Ten were males and ten were females. The ages ranged from 18 to 54 (mean $\pm \mathrm{SD}=33.5 \pm 9.1$ ). The duration of the seizures of the group ranged from 6-40 years (mean \pm $\mathrm{SD}=22.9 \pm 9.9$ ). All had partial seizures without or with secondary generalization. The majority of the patients had idiopathic seizures ${ }^{[16]}$ and the others had symptomatic epilepsy $^{[4]}$ that were considered to be due to chronic nonprogressive conditions. One patient did not participate beyond the initial 12 week baseline period and 19 patients received the drug.

The dosages ranged from 6.2 - 14 mg.kg.day ${ }^{-1}$ (mean $\pm \mathrm{SD}=7.8 \pm 2.3$ ). Of the 19 patients who received the drug, one patient dropped out due to a skin rash and two patients withdrew from the study due to personal reasons and were not included in the analysis. Of the 16 patients who completed the study, $56.3 \%$ had better than $50 \%$ reduction in their overall seizure frequency compared to their own baseline seizure frequency (Table 1). Six patients had simple partial seizures (SPS) in addition to complex partial seizures (CPS). Four of these (66.7\%) had significant reduction in the frequency of SPS (Table 2). Seven patients had partial seizures with secondary generalization (SGTC) and 6 of them (85.7\%) had significant improvement in the frequency of their SGTC. The average plasma levels for these patients ranged from

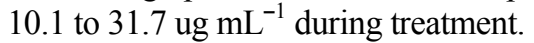

Side-effects were reported by eight patients. One had a skin rash requiring discontinuation of the medication. Seven others reported nausea, decreased appetite, fatigue, confusion, slowing of thinking, malaise, abdominal discomfort, balance difficulties, lightheadedness, weight loss, nervousness, drowsiness, headache, weakness and sluggishness. These symptoms responded to dosage reduction. None had significant alterations in $\mathrm{CBC}$, platelets or SMA 16. It was concluded that zonisamide was well tolerated and the only major side effect that required discontinuation of treatment was the development of a drug rash in one patient.
Mechanism of action: ZNS, 1,2-benzisoxazole 3methanesulfonamide, is a sulfonamide derivative and was first synthesized by Uno et al. ${ }^{[4]}$. It is chemically distinct from all other AED's. It has been shown to be a weak carbonic anhydrase inhibitor ${ }^{[5]}$, but that does not constitute its anticonvulsant mechanism. ZNS blocks Ttype calcium currents in a dose dependent fashion with no effect on L-type calcium-currents. Kito et al. ${ }^{[6,7]}$, have shown that ZNS can block T-type $\mathrm{Ca}^{++}$channels. They showed that it can suppress the inward current that underlies the epileptiform cellular bursting, thereby inhibiting the spread of seizure activity. In addition, ZNS can block voltage sensitive $\mathrm{Na}^{+}$channels ${ }^{[8]}$, modulate the dopaminergic system ${ }^{[9]}$ and accelerate GABA release ${ }^{[10]}$. In animal models, ZNS also prevented the tonic extensor component of maximal electroshock seizure ${ }^{[11]}$ and attenuated or controlled fully kindled seizures. It has also been shown to abolish seizures induced by pentylenetetrazole.

Pharmacokinetics: Several Japanese studies $^{[12,13]}$ demonstrated a linear relationship between the doses and the plasma concentrations of ZNS. However, in the US, where multiple dose regimens were given to patients, a nonlinear pharmacokinetics ${ }^{[14,15]}$ with first order clearance, was reported. Peak plasma concentration $\left(\mathrm{C}_{\max }\right)$ following oral ZNS were achieved within 2.4 to $3.6 \mathrm{hrs}$ in healthy volunteers in the US. Plasma elimination half-life ranged from 50 to $68 \mathrm{hrs}$ after a single oral dose of 200 to $800 \mathrm{mg}$. After oral administration ZNS undergoes acetylation and cleavage of the isoxazole ring followed by conjugation with glucuronic $\operatorname{acid}^{[16,17]}$. The majority of the drug is eliminated through the kidneys in healthy volunteers. However, renal dysfunction does not seem to have a significant effect on the elimination of ZNS and may prove to be useful for patients with renal disease. The gastrointestinal tract also may also play a part in its elimination.

Initial clinical trials in the US: The earliest study of ZNS in the USA was by Sackellares et al. ${ }^{[18]}$. In this pilot trial, 9 of the 10 patients had significant reduction in seizures, with no change in one. ZNS was compared to CBZ in a monotherapy trial of 12 weeks duration in 8 patients by Wilensky et al. ${ }^{[15]}$, in which the drug was found to be efficacious in five. Of note was the development of a mild Steven Johnson's syndrome in one patient who was withdrawn from the study. The best response occurred at a level of $20-30 \mathrm{mg} \mathrm{L}^{-1}$, after which drug toxicity was noted. The largest US trial was reported by Leppick et al. ${ }^{[19]}$. This was a noncomparative, multi-center trial of 167 patients with 
Am. J. Pharm. \& Toxicol., 2 (2): 60-64, 2007

Table 1: Response to treatment by participants

\begin{tabular}{|c|c|c|c|c|c|c|}
\hline \multirow[t]{3}{*}{ No. ID } & \multirow[t]{3}{*}{ Age } & \multicolumn{3}{|c|}{ Average \# of seizures per week } & \multicolumn{2}{|l|}{ Seizure reduction } \\
\hline & & During & During & $\%$ change & $<50 \%$ & $>50 \%$ \\
\hline & & Observation & Treatment & & & \\
\hline 1. MED & 26 & 10.9 & 4.0 & -63.3 & --- & $\mathrm{X}$ \\
\hline 2. GGJ & 33 & 2.5 & 1.6 & -36.0 & $\mathrm{X}$ & --- \\
\hline 3. $\mathrm{ABW}$ & 54 & 5.9 & 3.5 & -40.6 & $\mathrm{X}$ & --- \\
\hline 4. LDE & 34 & 0.8 & 0.0 & -100.0 & --- & $\mathrm{X}$ \\
\hline 5. $\mathrm{CAC}$ & 39 & 2.3 & 1.7 & -26.1 & $\mathrm{X}$ & --- \\
\hline 6. EEO & 45 & 57.9 & 45.1 & -22.1 & $\mathrm{X}$ & --- \\
\hline 7. TRW & 23 & 6.0 & 13.8 & +130.0 & $\mathrm{X}$ & --- \\
\hline 9. PSS & 33 & 3.5 & 0.0 & -100.0 & --- & $\mathrm{X}$ \\
\hline 14. ALW & 39 & 1.0 & 0.3 & -70.0 & --- & $\mathrm{X}$ \\
\hline 15. SLR & 28 & 1.6 & 0.5 & -68.7 & --- & $\mathrm{X}$ \\
\hline 16. $\mathrm{PAB}$ & 20 & 2.3 & 1.5 & -34.8 & $\mathrm{X}$ & --- \\
\hline 17. $\mathrm{CMF}$ & 37 & 2.0 & 0.7 & -65.0 & --- & $\mathrm{X}$ \\
\hline 18. CTD & 29 & 2.2 & 0.8 & -63.6 & --- & $\mathrm{X}$ \\
\hline 19. REB & 36 & 2.0 & 0.8 & -60.0 & --- & $\mathrm{X}$ \\
\hline 21. YAD & 39 & 7.2 & 2.9 & -59.0 & --- & $\mathrm{X}$ \\
\hline 22. DAM & 21 & 1.8 & 2.2 & +22.0 & $\mathrm{X}$ & --- \\
\hline 8. LCW & $22^{1}$ & --- & --- & --. & --- & --- \\
\hline 12. SLF & $18^{2}$ & --- & --- & --- & --- & --- \\
\hline 13. DED & $30^{3}$ & --- & --- & --- & --- & --- \\
\hline 23. DJC & $31^{4}$ & --- & --- & --- & & \\
\hline \multicolumn{7}{|c|}{$1 \quad$ Decided not to receive $\mathrm{z}$} \\
\hline Drop & & 1 reasons. & & & & \\
\hline Rem & n stu & o drug rash. & & & & \\
\hline Drop & due t & al reasons. & & & & \\
\hline
\end{tabular}

refractory partial seizures. ZNS was used as 'add-on' therapy at doses of $50-1100 \mathrm{mg} \mathrm{day}^{-1}$ for 16 weeks. The monthly seizure frequency decreased from 11.5 at baseline to 5.5 during the final month $(\mathrm{p}<0.01)$. The overall seizure frequency was $>50 \%$ in $40.9 \%$ of all patients. Kidney stones were detected in four patients (3.5\%) and were withdrawn from the study 250-477 days after the initiation of ZNS.

Toxicity profile: Data on toxicity have been based on Japanese studies, until the recent US trials ${ }^{[19,20]}$. In the pooled Japanese data of 1008 patients from four studies $^{[21]}$, the most frequent adverse effects were drowsiness $(24 \%)$, ataxia $(13 \%)$, loss of appetite $(11 \%)$, gastrointestinal problems (7\%), loss or decreased spontaneity (6\%) and slowing of mental activity (5\%). In another study ${ }^{[22]}$, ZNS was compared with $\mathrm{CBZ}$ and ataxia was noted to be more frequent with CBZ and loss of appetite occurred more often in patients receiving ZNS. In a 12 week double blind paradigm in Europe involving139 patients $^{[23]}$ adverse effects occurred in $59.2 \%$ of patients $(\mathrm{n}=71)$ taking ZNS compared to $27.9 \%$ in the placebo group $(n=68)$. The most frequently seen adverse effects in the ZNS group were fatigue $(22.5 \%)$, somnolence $(14.1 \%)$, dizziness $(16.9 \%)$, ataxia $(11.3 \%)$ anorexia $(12.7 \%)$, abnormal thinking $(11.3 \%)$, nervousness $(9.9 \%)$ and confusion (5.6\%). ZNS was withdrawn in two patients due to adverse effects. Renal calculi were not observed nor any relevant changes in clinical chemistries or hematological analyses were seen.

In the noncomparative study, conducted in the $\mathrm{US}^{[19]}$, the short term use of ZNS (16 weeks) resulted in $81.4 \%$ of all patients $(n=167)$ reporting at least one adverse effect. And $12.6 \%(\mathrm{n}=21)$ patients withdrew from therapy due to one of the following adverse events namely somnolence, headache, nausea, vomiting, dizziness, anorexia, confusion, ataxia fatigue and skin rash. The long term (108 weeks) tolerability of ZNS was assessed in the same study and more than $15 \%$ of patients developed adverse effects, which were mainly dizziness, headache, nausea, vomiting and anorexia. Six patients $(5.3 \%)$ withdrew from therapy due to central nervous system side effects and $10(8.8 \%)$ due to other side effects. It is notable that in this trial, 4 of 113 patients $(3.5 \%)$ withdrew from the study due to report of stone formation. Two of those patients, had a positive family history for nephrolithiasis. In the combined US and European pool ${ }^{[24]}, 13$ of 700 patients $(1.9 \%)$ developed renal calculi. These findings led to a suspension of trials within the US. The causal relationship of this finding is still disputed. In contrast, only 2 (both male) of 1008 patients $(0.2 \%)$ treated with ZNS were found to have urinary lithiasis and both patients had history of nephrolithiasis in one parent. 
Table 2: Response to treatment by seizure type

\begin{tabular}{lccl}
\hline $\begin{array}{l}\text { Seizure } \\
\text { Type }\end{array}$ & $\begin{array}{l}\text { Number of } \\
\text { Patients }\end{array}$ & $\begin{array}{l}\text { Significant } \\
\text { Reduction }\end{array}$ & $\begin{array}{l}\text { Non-significant } \\
\text { Reduction/Increase }\end{array}$ \\
\hline Simple Partial & 6 & $4(66.7 \%)$ & $2(33.7 \%)$ \\
$\begin{array}{l}\text { Complex Partial } \\
\text { Secondarily }\end{array}$ & 16 & $9(56.3 \%)$ & $7(43.7 \%)$ \\
Generalized & 7 & $6(85.7 \%)$ & $1(14.3 \%)$ \\
\hline
\end{tabular}

They also experienced spontaneous elimination of the calculi.

Other rare side effects include oligohydrosis or decreased sweating ${ }^{[25]}$, ZNS-induced behavior disorders $^{[26]}$ at plasma ZNS levels within or even below the therapeutic range and one case of IgA and IgG2 deficiency associated with the ZNS therapy ${ }^{[27]}$. In one Japanese survey of 381 hospitals between 1989 and 1994, twenty-six, infants were exposed to ZNS prior to delivery. Of these, four were exposed to ZNS alone and others to multiple drugs. Of those, 22 were on polypharmacy, with one case of anencephaly and one of atrial septal defect, suggesting that the risk of ZNS teratogenicity is no greater than that of other conventional AEDs. However, such risk cannot be neglected even at therapeutic dosages or concentrations of ZNS, particularly because of the small sample size of this study.

Dosage and administration: Recommended initial adult dosage in Japan is $100-200 \mathrm{mg} \mathrm{day}^{-1}$, increased if necessary to 200-400 $\mathrm{mg} \mathrm{day}^{-1}$, up to a maximum of $600 \mathrm{mg}$ day $^{-1}$. In children, initial dosage is 2-4 mg.kg.day ${ }^{-1}$, increased if necessary to $4-8 \mathrm{mg} . \mathrm{kg}^{- \text {day }^{-1}}$ up to a maximum of $12 \mathrm{mg} \cdot \mathrm{kg} \cdot \mathrm{day}^{-1}$. The recommended therapeutic plasma ZNS concentration is $10-20 \mathrm{mg} \mathrm{L}^{-1}$. Adverse events have been noted with plasma ZNS concentrations of $>30 \mathrm{mg} \mathrm{L}^{-1}$ which were mainly drowsiness, loss of appetite, gastrointestinal problems and CNS toxicity. A drug rash also has been reported. In Japan, ZNS is available in a $100 \mathrm{mg}$ tablet and a $200 \mathrm{mg} \mathrm{gm}^{-1}$ powder formulation. The recommended therapeutic plasma ZNS concentration is $10-20 \mathrm{mg} \mathrm{L}^{-1}$. Clinical investigations have demonstrated adverse events with plasma ZNS concentration of more than $30 \mathrm{mg} \mathrm{L}^{-1}$, thus suggesting the usefulness of therapeutic drug monitoring. In the US, it is marketed as 25,50 and $100 \mathrm{mg}$ capsules and is also available in generic formulation.

Due to the potential for causing teratogenic effects on offspring of pregnant women taking ZNS, as noted before, it may be administered to pregnant women only if the therapeutic benefits outweigh the potential hazards. In Japan ZNS is not recommended for use by nursing mothers, as it is excreted in milk ${ }^{[28]}$. However, if the mother had been using ZNS during pregnancy, nursing may help prevent rapid withdrawal of the drug from the infant following exposure in utero.

\section{CONCLUSION}

ZNS is an effective AED as shown by several studies conducted Japan, USA and Europe. The antiepileptic efficacy of ZNS is similar to that of the standard AEDs and the newer agents, in clinical trials using it as 'add-on' drug in patients with refractory partial epilepsy. It has a long half-life, which affords single daily dosage and improving compliance. Another advantage of ZNS is that it is well absorbed after oral use and it can be prescribed without regard to time of meal. Although, the initial marketing attempt in the USA was abandoned in the late 80 's, renewed interest in the drug has resulted in a new multicenter trial in the US and subsequent approval by the FDA. The question of nephrolithiasis remains and warrants careful drug monitoring, until the question can be resolved with post marketing data.

\section{REFERENCES}

1. Hauser, W.A. and D.C. Hesdorffer, 1991. Facts About Epilepsy. New York, NY: Demos, 1.

2. Theodore, W.H., Spencer, S.S. Wiebe, S., Langfitt, J.T., Ali, A., Shafer, P.O., Berg, A.T., Vickrey, B.G., Epilepsy in North America: A Report Prepared under the Auspices of the Global Campaign against Epilepsy, the International Bureau for Epilepsy, the International League Against Epilepsy, and the World Health Organization, October 2006. Epilepsia, 47(10):1700-1722.

3. Mattson, R.H., J.A. Crammer and J.F. Collins, 1986. VA epilepsy co-operative study group. Success with alternate anti-epileptic drug selection. Epilepsia, 27: 645.

4. Uno, H., M. Kurokawa, K. Natsuka, Y. Yamato and H. Nishimura, 1976. Studies on 3-substituted 1,2benzisoxazole derivatives. Chem. Pharm. Bull., 24: 632-643.

5. Masuda, Y. and T. Karasawa, 1993. Inihibitory effect of zonisamide on human carbonic anhydrase in vitro. Arzneimittelforschung, 43: 416-418.

6. Kito, M., M. Maehara and K. Watanabe, 1994. Antiepileptic drugs-calcium current interaction in cultured human neuroblastoma cells. Seizure, 3: 141-149. 
7. Kito, M., M. Maehara and K. Watanbe, 1996. Mechanisms of T-type calcium channel blockade by zonisamide. Seizure, 5: 115-119.

8. Schauf, C.L., 1987. Zonisamide enhances slow sodium inactivation in Myxicola. Brain Res., 413: 185-188.

9. Okada, M., S. Kaneko, T. Hirano, K. Mizuno, T. Kondo, K. Otani and Y. Fukushima, 1995. Effects of zonisamide on dopaminergic system. Epilepsy Res., 22: 193-205.

10. Endo, A., 1995. Effect of zonisamide on neurotransmitter release from hippocampal slice of El mice: A study of neurotransmitter release using an improved experimental system. Okayama Igaku Zasshi, 107: 69-78 (in Japanese).

11. Masuda, Y., T. Karasawa and Y. Shiraishi et al., 1980. 3-Sulphamoylmethyl-1,2-benzisoxazole, a new type of anticonvulsant drug. Pharmacological Profile. Arzneimittel-Forschung/Drug Res., 30: 477-483.

12. Yagi, K., M. Seino and T. Mihara et al., 1987. Open clinical trial of a new antiepileptic drug, zonisamide on 49 patients with refractory epileptic seizures. Seishin Igaku, 29: 111-119 (in Japanese).

13. Ono, T., K. Yagi and M. Seino, 1988. Clinical efficacy and safety of a new antiepileptic drug, zonisamide - a multi-institutional phase III study. Seishin Iyaku, 30: 471-482 (in Japanese).

14. Wagner, J.G., J.C. Sackellares, P.D. Donofrio, S. Berent and E. Sakmar, 1984. Nonlinear pharmacokinetics of CI-912 in adult epileptic patients. Therapeutic Drug Monitoring, 6: 277-283.

15. Wilensky, A.J., P.N. Friel, L.M. Ojemann, C.B. Dodrill, McCormick and R.H. Levy, 1985. Zonisamide in epilepsy: A pilot study. Epilepsia, 26: 212-220.

16. Ito, T., T. Yamaguchi and H. Miyizaki et al., 1982. Pharmacokinetic studies ofAD-180, a new antiepileptic compound. ArzneimittelForschung/Drug Res., 32: 1581-1586.

17. Matsumoto, K., H. Miyazaki and T. Fuji et al., 1983. Absorption, distribution and excretion of 3(sulphamoyl $\left[{ }^{14} \mathrm{C}\right]$ methyl)-1,2-benzisoxazole (AD810)in men. Arzneimittel-Forschung/Drug Res., 33: 961-968.
18. Sackellares, J.C., P.D. Donofrio, J.G. Wagner, B. Abou-Khalil, S. Berent and K. Aasved-Hoyt, 1985. Pilot study of zonisamide (1,2-benisoxazole-3methansulfonamide) in patients with refractory partial seizures. Epilepsia, 26: 206-211.

19. Leppick, I.E., L.J. Willmore and R.W. Homan et al., 1993. Efficacy and safety of zonisamide: Results of a multicenter study. Epilepsy Res., 14: 165-173.

20. Sackellares JC, Ramsay RE, Wilder BJ, Browne TR III and Shellenberger MK, 2004. Randomized controlled clinical trial of zonisamide as adjunctive treatment for refractory partial seizures. Epilepsia 45 (6); 610-617

21. Yagi, K. and M. Seino, 1992. Methodological requirements for clinical trials in refractory epilepsies - our experience with zonisamide. Prog. Neuro-Psychopharmacol. \& Bio-Psychia, 16: 7985.

22. Seino, M., T. Ohkuma and M. Miyasaka et al., 1988. Efficacy evaluation of AD-180 (zonisamide)- results of a double -blind comparison with carbamezepine (CBZ). Igaku no Ayumi, 144: 275-291 (in Japanese).

23. Schmidt, D., P. Loiseau and R. Jacob et al., 1993. Zonisamide for add-on treatment of refractory partial epilepsy: A European double-blind trial. Epilepsy Res., 15: 67-73.

24. Henry, T.R. and J.C. Sackellares, 1992. The Medical Treatment of Epilepsy., pp: 423-427, Marcel Dekker Inc., New York,

25. Okumura, A., F. Hayakawa, K. Kuno and K. Wantanabe, 1996. Oligohidrosis caused by zonisamide. No To Hattatsu, 28: 44-47 (in Japanese).

26. Kimura, S., 1994. Zonisamide-induced behavior disorder in two children. Epilepsia, 35: 403-405.

27. Maeoka, Y., T. Hara, S. Dejima and K. Takeshita, 1997. IgA and IgG2 deficiency associated with zonisamide therapy: A case report. Epilepsia, 38: 611-613.

28. Peters, D.H. and E.M. Sorkin, 1993. Zonisamide-A review of its pharmacodynamic and pharmacokinetic properties and therapeutic potential in epilepsy. Drugs, 45: 760-787. 